\title{
Macrophage Colony Stimulating Factor Measurement
}

National Cancer Institute

\section{Source}

National Cancer Institute. Macrophage Colony Stimulating Factor Measurement. NCI

Thesaurus. Code C80191.

The determination of the amount of macrophage colony stimulating factor present in a sample. 